\title{
Energy transitions in urban China: Drivers, developments and challenges
}

Ping Huang, Rasmus Lema² and Xing Li3

'The Urban Institute, University of Sheffield; '2Department of Business and Management, Aalborg University;

${ }^{3}$ Department of Politics and Society, Aalborg University

\begin{abstract}
Introduction
The past few decades have witnessed unprecedented industrialization and urbanization in China. By the end of 2019 , more than $60 \%$ of the population were living in urban areas, as compared to only $17.92 \%$ in 1978 (National Bureau of Statistics 2020). However, rapid urbanization is giving rise to mounting pressures related to energy security, resource scarcity and environmental degradation in contemporary China. As a response, the Chinese government has highlighted green development as one of its main national development strategies, supported in more detail by a series of sectoral and technological guidelines for the transition and upgrading towards a green and low-carbon economy.
\end{abstract}

It is widely agreed that China is making substantial inroads in sustainable energy production and consumption (Zhou et al. 2020). Cities are major contributors to climate change, consuming over two-thirds of the world's energy, and producing more than $70 \%$ of all carbon dioxide emissions (C4O Cities Climate Leadership Group 2020). The energy-related CO2 emissions and energy consumption of China's cities accounts for 58\% (Stockholm Environment Institute 2020) and 75\% respectively of the country's totals (Cheng et al. 2019). Cities are therefore at the frontier of forging low-carbon transitions, and they possess tremendous potential as 'innovation hubs' for sustainability (Castán Broto and Bulkeley 2013).

As one of the largest countries in the world in terms of its population and geographical size, and increasingly its GDP, China provides a large experimental field for energy transitions. In Chinese cities, numerous projects have proliferated in different sectors experimenting with new solutions for the deep decarbonization of the existing energy production, distribution and consumption system. Focusing on energy transitions in urban China, this chapter presents a brief overview of the rationales for a transition, transition practices and the challenges faced by Chinese cities in the transition.

\section{Drivers of energy decarbonization in China}

In recent years, Chinese cities have made substantial achievements in the decarbonizing urban systems. This 'green' turn is a response to several challenges that have become increasingly evident and acute after three decades of rapid economic growth and urbanization.
The cultivation of an 'ecological civilization'

Since its economic reform of the late 1970s, China's top national priority has been economic development and poverty alleviation, environmental issues being considered less important. Due to long-term and large-scale applications of less environmentally friendly technologies in industry, environmental problems are becoming so severe that they can no longer be ignored. For instance, the well-known heavy smog in Beijing and many other mega-cities represents serious air pollution. In 2016, the air quality of $78.4 \%$ of China's cities were not up to standard (State Council 2016). Therefore, recent years have seen environmental protection assume increasing importance in public and political narratives in China. In March 2018, for the first time, 'ecological civilization' was written into the Chinese Constitution. Notably, controlling air and water pollution, promoting energy transformation and developing renewable energy are key tasks assigned to this national strategy. For instance, in China's $13^{\text {th }}$ Five-Year Plan it was specified that emissions of sulphur dioxide (SO2) and nitrogen oxides (NOx) must be reduced by 15 percent by 2020, and PM2.5 by 25 percent (State Council 2016).

\section{Building green innovation capacity}

China has also made remarkable achievements in the development of several new and renewable energy sectors, such as wind power and solar energy. China views these sectors as promising arenas in which it can take the lead not only in respect of manufacturing capacity but, more importantly, innovation capability as well. This ambition can be seen in policy initiatives launched by the central government in recent years. Starting with the period of the 12th Five-Year Plan (20112015), a special focus has been placed on the building of national innovation capacities. In 2013, the $12^{\text {th }}$ Five-Year National Independent Innovation Capacity Building Plan was published, which is China's first national plan and guiding document for the systematic enhancement of independent innovation capacity. The main objectives were to build and deepen innovation capabilities related to infrastructure, by building new partnerships, cultivating innovative talent and improving the overall innovation environment. This strategic policy emphasis on innovative capacity-building is further strengthened in the $13 \mathrm{th}$ Five-Year Plan for National Scientific and Technological Innovation. Specifically, for green innovation in the energy sector, two important documents were prom- 
ulgated: the Energy Technology Revolution Innovation Action Plan (2016-2030) released in March 2016, and the 13th Five-Year Plan for Energy Technology Innovation released later, in December 2016. These two documents put forward specific aims, measures and initiatives for advancing technological innovation in the energy sector. The main goal is to establish a comprehensive energy technological innovation system and to make breakthroughs in key technological areas such as renewable energy, smart grids and energy storage.

\section{Energy security in changing geopolitical circumstances}

Rapid and large-scale urbanization and industrialization have placed significant pressures on domestic energy supplies. Domestic energy resources are far from sufficient to meet the country's huge energy demand, and energy supplies are highly dependent on foreign imports. In 2017, China's dependence on foreign oil and natural gas reached $67.4 \%$ and $39 \%$ respectively (CNPC 2017). This poses serious questions for the stability of the country's energy supply and energy security. This situation, combined with changing geopolitical circumstances and the 'energy concern', is increasingly being taken into account in the geopolitical and geoeconomic calculations surrounding China's international relations. Energy-based international relations have become a core part of Beijing's national interest and its foreign-policy priority. For example, China's investment in renewable energy is increasing under the Belt and Road Initiative (PV Magazine 2019); China's energy ties with Russia are developing more strongly in terms of both the newly opened Russian gas pipeline to China and their joint ventures in energy exploration in the Arctic region; one of the aims of China's proactive defence policy in the South China Sea is to secure access to the region's energy reserves; and Chinese trade and investment in energy are becoming a pivotal part of China's economic relations with Africa and Latin America (The Economist 2016).

\section{Energy transition initiatives in urban China}

The Chinese government has assigned high importance to the mission to achieve the energy transition, in which respect cities are considered a critical arena.
Accomplishing an urban energy transition involves non-trivial processes of infrastructural reconfiguration through which new governance arrangements (such as urban laboratories and urban experimentation) are fitted to the actual landscape of intervention (Castán Broto 2015). It covers a wide range of sectors in the urban system such as manufacturing, electricity, transportation and construction. This section reviews three national-level initiatives in China that aim to promote low-carbon development in cities.

\section{The Low-carbon City Initiative}

In 2010, the National Development and Reform Commission (NDRC) initiated the Low-Carbon Province and City pilot program. Cities participating in this program are required to develop long-term plans for low-carbon development, design specific measures to reduce carbon emissions, and establish carbon emissions accounting and management systems (Lo 2014). Till now, three batches of designation have been announced successively in 2010, 2012 and 2017, covering a total of 71 cities (Table 1).

The Low-carbon City Initiative has a long history, having been a consistent and continuous low-carbon effort in China for the past decade. It takes many years to pilot new ideas and experiments, so while the latest batch of cities were designated in 2017, we still await the outcomes. According to some analysts, however, the implementation of this low-carbon city initiative has proved to play a positive role in reducing carbon emissions in the pilot cities (Cheng et al. 2019). Assessing the achievement of carbon-intensity targets during the $12^{\text {th }}$ five-year period showed that the decreases in carbon intensities in the pilot cities were significantly higher than the national average. In 2019, a 'Report on the Evaluation of Chinese Green and Low-carbon Cities' was released, which comprehensively evaluated the green and low-carbon performances of 169 Chinese cities, including the 71 low-carbon pilot cities. The report showed that in general, low-carbon pilot cities had a higher performance than non-pilot cities. Moreover, the performances of the first batch of pilot cities was significantly

Table 1 National low-carbon pilot cities in China. Source: Cheng et al. (2019).

Group Number of cities Names of cities

First batch (2010) 8

Second batch (2012) 27
Baoding, Chongqing, Guiyang, Hangzhou, Nanchang, Shenzhen, Tianjin, and Xiamen

Beijing, Chizhou, Ganzhou, Guangyuan, Guangzhou, Guilin, Huai'an, Hulun Buir, Jilin, Jinchang, Jincheng, Jingdezhen, Kunming, Ningbo, Nanping, Qingdao, Qinhuangdao, Shanghai, Shijiazhuang, Suzhou, Urumqi, Wenzhou, Wuhan, Yan'an, Zhenjiang, and Zunyi

Ankang, Changsha, Changzhou, Chaoyang, Chengdu, Chenzhou, Dalian, Fuzhou, Hefei, Huaibei, Huangshan, Ji'an, Jiaxing, Jinan, Jinhua, Lanzhou, Lasa, Liuzhou, Lu’an, Nanjing, Pu'er, Quzhou, Sanming, Sanya, Shenyang, Weifang, Wuhai, Wuzhong, Xiangtan, Xining, Xuancheng, Yantai, Yinchuan, Yuxi, Zhuzhou, and Zhongshan 
better than those of later batches, indicating that the effectiveness of the policy takes longer to manifest itself. The report verified the positive outcomes generated by the Low-carbon City Initiative and recommended further deepening and scaling-up of the pilot scheme in China.

\section{The 'Ten Cities, One Thousand Vehicles' program}

As early as the period of the $8^{\text {th }}$ five-year plan (1991-1995) the Chinese central government started developing new energy vehicles (NEV)s. On the one hand, the NEV industry was regarded as a strategic industry with emerging advanced technologies that can ensure energy security, promote industrial restructuring and create new job opportunities; on the other hand (echoing global environmental challenges), considered as a substitute for ICE vehicles, NEVs were expected to mitigate the impacts of climate change and decarbonize the energy system. The implementation of an NEV industry has been highlighted in many national plans and strategies. A rey national initiative for implementing NEV in cities is the 'Ten Cities, One Thousand Vehicles' program. This initiative was launched in 2009 with the aim of introducing a thousand NEVs in ten cities every year for the following three years. The demonstration focused on public sectors such as government fleets and public transport. A total of 25 cities were selected as pilot cities for the initiative (Table 2). Under this initiative, the purchase of NEVs and the construction of charging infrastructure were subsidized by both the central government and local governments. The program planned to promote 53,697 vehicles in the 25 pilot cities. By the end of 2012, only half of the intended target had been achieved (Han et al. 2014). Seen from the perspective of implementation, the initiative can hardly be labelled a success. Nevertheless, the 'Ten Cities, One Thousand Vehicles' program acted as a prelude to large-scale subsidized programs for NEVs launched at later stages. Since 2015, according to data released by the China Association of Automobile Manufacturers, the market for NEVs in China has expanded significantly, their market share having increased from 1.34\% in 2015 to $4.68 \%$ in 2019.

\section{Mandatory implementation of building-integrated solar water-heating systems}

The building sector is a main contributor to energy consumption and carbon emissions in urban areas. Statistics show that the energy consumption of buildings accounts for $20.7 \%$ of the total end energy consumption in China (Cai et al. 2009). The Chinese

\section{The Energy Transition in Zhangfiakou City}

Zhangjiakou, a city of 4.4 million people in Hebei Province, sets an example to other cities in China and worldwide of how to take advantage of renewables and transform an energy system. Zhangjiakou possesses abundant renewable energy resources and has the potential to lead the world in low-carbon development. Over the past decade, the city has stepped up its efforts to deploy renewable energy systems. In 2017, renewables accounted for $73 \%$ of the city's total installed capacity and for around $45 \%$ of its total electricity output. However, there is still the potential for 30 gigawatts (GW) of solar photovoltaic (PV) and $40 \mathrm{GW}$ of wind generation. The State Council of China has designated Zhangjiakou to become the country's first-ever National Renewable Energy Demonstration Zone. By 2050, the city could increase its use of renewables from less than half to nearly three quarters of its electricity mix. This is what an ambitious energy transformation plan for 2050 sets out to do. The municipal authorities in Zhangjiakou City, in co-operation with the China National Renewable Energy Centre (CNREC) and the International Renewable Energy Agency (IRENA), have adopted this ambitious thirty-year road map to phase out coal-fired power generation and scale up solar and wind power instead. The city is a pioneer in developing a comprehensive plan which includes changing technologies in use (e.g. from blast furnaces to electric arc furnaces in its steel production), smart manufacturing, hydrogen production and smart-grid technologies.

Source: IRENA 2019

government therefore regards the building sector as a critical arena for decarbonizing the energy system and introducing renewable energy to buildings constitutes a crucial part of urban energy transitions (He et al. 2015). In light of this, governments at multiple governance levels (i.e. both national and provincial

Table 2 Pilot cities in the 'Ten Cities, One Thousand Vehicles' initiative

\begin{tabular}{|c|c|c|}
\hline Group & Number of cities & Names of cities \\
\hline First batch & 13 & $\begin{array}{l}\text { Beijing, Changchun, Changsha, Chongqing, Dalian, Hangzhou, Hefei, } \\
\text { Jinan, Kunming, Nanchang, Shanghai, Shenzhen, Wuhan }\end{array}$ \\
\hline Second batch & 7 & Guangzhou, Haikou, Suzhou, Tangshan, Tianjin, Xiamen, Zhengzhou \\
\hline Third batch & 5 & Chengdu, Huhhot, Nantong, Shenyang, Xiangfan \\
\hline
\end{tabular}


level) have introduced a series of policy instruments to implement building-integrated renewable-energy systems in urban areas, the application of solar energy having become a central focus.

In 2006, an 'Implementation Opinion on the Application of Renewable Energy in Buildings' was published, stressing the necessity of scaling up renewable energy use in the building sector. Building-integrated solar water-heating technology was specified as one of the key areas for implementation. In 2007, the 'Notice on Accelerating the Application of Solar Thermal Systems' required provincial and urban governments to accelerate the application of building-integrated solar water-heating systems in buildings. According to incomplete statistics, by 2016, mandatory regulations had been enacted in twelve provinces and 25 cities in China requiring the integration of solar water-heating systems in newly built public and residential buildings under twelve floors. This mandatory policy has boosted market expansion in urban areas. However, it did not work well in all cases. In many cities, it was reported that installed solar systems were being left unused. In Shenzhen, for instance, of the 250 solar projects that were constructed, at least 56 had been left unused, representing a total investment of more than 90 million RMB.

\section{The International Dimension of Energy Transitions in Urban China}

International participation in developments in renewable energy in China in connection with the urban energy transition have increased. China benefits greatly from international cooperation in its efforts to achieve low-carbon urban development, such as accessing finance and technologies, developing human resources and enhancing the policy framework. According to one empirical study (Cheshmehzangi et al. 2018) of Shenzhen's International Low Carbon City (ILCC), a collaborative project on developing low-carbon city-planning initiatives in China in cooperation with multiple international partners (Germany, Italy, France, Australia and the US), Shenzhen, one of China's largest and richest high-tech cities, shows that the ILCC initiative benefits significantly from international cooperation. The study concludes that the positive roles of international collaborators in the success of Shenzhen's ILCC indicates 'a new and unique model of low carbon- and eco-development that includes multiple international actors, multiple involvements and multiple roles in the low-carbon transitions, which will provide a feasible technological integration and vibrant model for other cases' (Cheshmehzangi et al. 2018: 74).

China and Denmark are also cooperating closely in China's ambition to increase its share of non-fossil fuels in primary energy consumption to about 20\%. According to the Danish Energy Agency Partnership Program (2017-2020), Denmark will support China's energy transition to higher shares of renewable energy with experience and technical expertise based on the experience of the transition in the Danish energy system. Currently the two countries are engaged in many on-going projects in China in the areas of green development, renewable energy, district heating, quality offshore wind energy, etc. (Danish Energy Agency 2017). Chapter 8 in this report provides lessons from Sino-Danish collaboration on clean district heating and its integration into urban energy systems.

\section{The challenges of the energy transition faced by Chinese cities}

Of all the energy-related challenges that result from China's rapid industrialization, especially its unprecedented urbanization in recent decades, such as energy security, energy affordability and environmental sustainability, energy security is obviously the top concern. According to a research study based on a large amount of data (Li et al. 2019), urbanization can play a positive role in promoting energy efficiency that increases energy security. This is due to improvements in energy efficiency that are easier to achieve in urban areas than in rural areas, such as the economies of scale involved in district heating (Li et al. 2019). Despite some achievements, Chinese energy efficiency still needs to do more to reach the average level of European and OECD countries (Voïta 2018), which may go hand in hand with urbanization.

China has taken an aggressive approach to advancing energy transitions in urban areas. These initiatives, however, have had mixed outcomes. For instance, although the low-carbon initiative has now expanded to more cities in China, the scheme is often criticized for lacking an integrated vision of how to transform cities into low-carbon cities and the irrational designs of policies at the local level, which often lead to distortions in resource allocations and a loss of efficiency (Shinn 2008, Cheng et al. 2019). Similar problems have emerged in the mandatory implementation of building-integrated solar water-heating systems, mainly due to a mismatch between local contexts (e.g. building orientation and residents' energy use habits) and the targeted technology (Huang et al. 2018).

This reminds us that urban energy transitions are multifaceted processes that involve multiple urban actors and that interact closely with local economic and socio-spatial contexts. On the one hand, urban development priorities might define local governments' decisions regarding transition pathways; on the other hand, the decarbonization of the urban energy system would inevitably reconfigure urban infrastructure and reshape residents' social practices (Huang and Broto 2018). It is thus imperative for political visions to suit local contexts if they are to induce real changes. The dominance of a top-down approach in China's energy transition might result in a lack of flexibility, openness and inclusiveness, which are imperative if urban experimentation is to thrive. Although top-down policy measures can be effective and efficient in practice, they might also carry the greater risk and higher costs of transition failures. This institutional limitation is a major challenge faced by decision-makers in promoting urban energy transitions. 


\section{Conclusion}

Cities have become important 'actors' in global efforts to transform economies from fossil fuels to green energy. This is true both globally and in China. In this chapter we have reviewed the drivers, developments and challenges of energy transitions in urban China.

In terms of the drivers of energy decarbonization in urban China, we have highlighted energy security as one motivation and the underlying aim of constructing an 'ecological civilization' as another. However, we also emphasised the proactive attention being paid to green innovation capacity-building. Chinese cities are increasingly seeking to create and utilize green windows of opportunity to enhance the city-level innovative capacity of enterprises and relevant organizations (see Lema et al. 2020; also Chapter 10 in this report).
We have also described the ambition and increasing traction of city initiatives across the People's Republic, including low-carbon pilot cities and focused initiatives regarding sustainability-oriented technologies such as new energy vehicles and solar water heaters. As we showed, there is an important international dimension to these initiatives in which China both benefits from and contributes to collaboration revolving around the creation of new directions in urban planning and development.

Finally, we have stressed that, while China has already made great strides in achieving urban energy transitions, there are still significant challenges to be overcome. We have also emphasised how bottom-up approaches may help to avoid city-level failures of the transition (Huang and Broto 2018) and facilitate the creation of just sustainabilities in urban communities (Agyeman and Evans 2003).

\section{References}

Agyeman, J., and Evans, T. 2003. 'Toward Just Sustainability in Urban Communities: Building Equity Rights with Sustainable Solutions'. ANNALS of the American Academy of Political and Social Science, 590(1): pp. 35-53.

Broto, V.C. and Bulkeley, H. 2013. 'A survey of urban climate change experiments in 100 cities'. Global environmental change, 23(1): pp. 92-102.

C40 Cities Climate Leadership Group. 2020. 'A Global Opportunity for Cities to Lead.' Retrieved September 8, 2020 (https://www.c40.org/why_cities).

Cai, W. G., Wu, Y., Zhong, Y. and Ren, H. 2009. 'China building energy consumption: situation, challenges and corresponding measures'. Energy policy, 37(6): pp. 2054-2059.

Castán Broto, V. 2015. 'Contradiction, intervention, and urban low carbon transitions'. Environment and Planning D: Society and Space, 33(3): pp. 460-476.

Cheng, J., Yi, J., Dai, S. and Xiong, Y. 2019. 'Can low-carbon city construction facilitate green growth? Evidence from China's pilot low-carbon city initiative'. Journal of cleaner production, 231: pp. 1158-1170.

Cheshmehzangi, A., Xie, L.J. and Tan-Mullins, M. 2018. 'The role of international actors in low-carbon transitions of Shenzhen's International Low Carbon City in China'. Cities, 74: pp. 64-74.
CNPC Economics \& Technology Research Institute. 2017. Oil and gas industry development report at home and abroad in 2017. Beijing: Petroleum Industry Press. (in Chinese)

Danish Energy Agency. 2017. Danish Energy Partnership Programme. https://ens.dk/sites/ens.dk/files/Globalcooperation/Publications_reports_papers/danish_energy_partnership_programme.pdf

Han, W., Zhang, G., Xiao, J., Bénard, P. and Chahine, R. 2014. 'Demonstrations and marketing strategies of hydrogen fuel cell vehicles in China'. International Journal of Hydrogen Energy, 39(25): pp. 13859-13872.

He, G., Zheng, Y., Wu, Y., Cui, Z., and Qian, K. 2015. 'Promotion of building-integrated solar water heaters in urbanized areas in China: Experience, potential, and recommendations'. Renewable and Sustainable Energy Reviews, 42: pp. 643-656.

Huang, P. and Broto, V.C. 2018. 'Interdependence between urban processes and energy Transitions: The dimensions of urban energy transitions (DUET) framework'. Environmental Innovation and Societal Transitions, 28: pp. 35-45.

Huang, P., Broto, V.C., Liu, Y. and Ma, H. 2018. 'The governance of urban energy transitions: A comparative study of solar water heating systems in two Chinese cities'. Journal of Cleaner Production, 180: pp. 222-231. 
Lema, R., Fu, X. and Rabellotti, R. 2020. 'Green windows of opportunity? Latecomer development in the age of transformation towards sustainability.' Industrial and Corporate Change, 29(5): pp xxxxxx.

Li, M., Li, L., and Strielkowski, W. (2019). The impact of urbanization and industrialization on energy security: A case study of China. Energies, 12(11): p. 2194.

Lo, K. 2014. 'A critical review of China's rapidly developing renewable energy and energy efficiency policies'. Renewable and Sustainable Energy Reviews, 29: pp. 508-516.

PV Magazine. 2019. 'Chinese investment in renewables soars under Belt \& Road initiative', 30 July. https:// www.business-humanrights.org/en/study-shows-chinese-investment-in-renewable-energy-increases-under-belt-and-road-initiative-O

Sinn, H.W. 2008. 'Public policies against global warming: a supply side approach'. International Tax and Public Finance, 15(4): pp. 360-394.

State Council. 2016. 国务院关于印发'十三五”生态环境 保护规划的通知 (Notice of the State Council of the 13th Five-Year Plan for Ecological Environment Protection).
No. SC [2016]65, 24 November 2016. http://www.gov.cn/ zhengce/content/2016-12/05/content_5143290.htm.

Stockholm Environment Institute. 2020. 'Chinese Cities As Leaders in Greenhouse Gas Emissions Reduction Efforts | Bloomberg Philanthropies.' Retrieved September 8, 2020 (https://www.bloomberg.org/press/releases/chinese-citiesas-leaders-in-greenhouse-gas-emissions-reduction-efforts/).

The Economist. 2016. 'The evolving role of China in Africa and Latin America'. https://lampadia.com/assets/uploads_documentos/7ffa7-the-evolving-role-of-china-in-africa-and-latin-america.pdf

Voïta, T. 2018. The Power of China's Energy Efficiency Policies. Ifri, Centre for Energy. https://www.ifri.org/sites/ default/files/atoms/files/voita_power_china_2018.pdf

Wang, Y., Song, Q., He, J. and Qi, Y. 2015. 'Developing low-carbon cities through pilots'. Climate Policy, 15(supl): pp. S81-S1O3.

Zhou, N., Lu, H., Khanna, N., Liu, X., Fridley, D., Price, L. and Ding, C. 2020. China Energy Outlook: Understanding China's Energy and Emissions Trends. Retrieved from https:// china.lbl.gov/china-energy-outlook



